\title{
Paideusis
}

\section{Philosophical Clashes: Rethinking Scholarship}

\section{Carlo Ricci}

Volume 18, Number 2, 2009

URI: https://id.erudit.org/iderudit/1072332ar

DOI: https://doi.org/10.7202/1072332ar

See table of contents

Publisher(s)

Canadian Philosophy of Education Society

ISSN

0838-4517 (print)

1916-0348 (digital)

Explore this journal

Cite this document

Ricci, C. (2009). Philosophical Clashes: Rethinking Scholarship. Paideusis, 18(2),

55-59. https://doi.org/10.7202/1072332ar

(C) Carlo Ricci, 2009

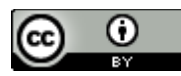

This document is protected by copyright law. Use of the services of Erudit (including reproduction) is subject to its terms and conditions, which can be viewed online.

https://apropos.erudit.org/en/users/policy-on-use/
This article is disseminated and preserved by Érudit.

Érudit is a non-profit inter-university consortium of the Université de Montréal, Université Laval, and the Université du Québec à Montréal. Its mission is to promote and disseminate research.

https://www.erudit.org/en/ 


\title{
Philosophical Clashes: Rethinking Scholarship
}

\author{
CARLO RICCI \\ Nipissing University, Canada
}

What counts as scholarship needs to be expanded to include more democratic forms. Those of us whose philosophy is in agreement with this need to take charge and act in ways consistent with this world view. Paraphrasing Gandhi, the way to change the world is to act in ways that are consistent with the change we want to see, to act as if the change has already happened. We need to feel empowered, and hopefully this paper is a step in helping people feel that they are not alone and their belief that scholarship needs to be democratized is legitimate. For far too long the definition of scholarship has been too limiting by being defined as what gets credited and rewarded as valuable work. In part, the limiting nature of scholarship is the result of forcing scholars to comply and conform to the narrow vision of, for example, peer reviewed work. This is especially problematic if we consider that peer reviewed work is not a neutral, objective, pure, error free process.

At the university where I work the definition of scholarship has been expanded in official documents and for the purposes of tenure and promotion, for example. Nevertheless, this laudable expansion continues to be derailed by those who still insist that there is a legitimate hierarchy, with peer reviewed publications at the top. In some cases, other publications follow, and in other cases anything that is not peer reviewed is dismissed. Some believe that there should be a weighting of various types of works and treat the ranking as if it is divined, rather than seeing the traditional standard of scholarship for what it is: an arbitrarily constructed, limiting convention. There are those who, if they had their way, would have us still writing on tablets in hieroglyphics.

I am well known in my circle and I am often told by people that the work that I am doing is having a significant impact on their lives and the lives of others around them. Nonsensically, many of the real world substantive benefits that are making a difference in people's everyday lived experiences are not considered to be scholarship on many peer reviewed competitions: for example, external grants, or tenure and promotion. I am asked to do talks, I am invited to write papers, my papers are readily accepted in prominent magazines and journals in my field, I do a lot of volunteer work, and so on. Absurdly, much of this laudable work that many of us do so well and that is so beneficial too often counts for little or nothing at all. There is something absurd about a peer reviewed paper that has far less impact, trumping real life world actions.

\section{The Need to Expand Scholarship}

Although many academics are doing wonderful and cutting edge work, those who are in positions to recognize the innovative work that is being done need to catch up. I am talking about simply legitimizing existing and accessible technologies, like YouTube, blogs, self publishing, wiki publishing, magazines, compact disk, and other such media. Unfortunately, there are still too many in positions of power whose actions lead me to conclude that they feel threatened by these more democratic means. They belittle these legitimate and laudable mediums as being unscholarly.

(C) Copyright 2009. The author, Carlo Ricci, assigns to Paideusis the right of first publication and educational and non-profit institutions a non-exclusive license to use this document for personal use and in courses of instruction provided that the document is used in full and this copyright statement is reproduced. Any other usage is probibited without the express permission of the author. 
By excluding cutting edge types of publications and types of scholarship in favour of peer reviewed publications, for example, we are restricting creativity, imagination, and talent. Too often, being published in a journal just means that you are working within the paradigm of the journal editors, and that you were forced to conform to their formulas, ideas, and beliefs. Peer review simply means that your work is consistent with the philosophy of the reviewers. The danger of this is that if you hold a world view that is consistent with the majority then there is a lot of opportunity and options for you to publish in mainstream spaces; there, you will get recognition from those in a position to make decisions allowing you opportunities to continue in pursuing your work. For example, you may get access to funds and release time. Unfortunately, if this isn't the case, then you are punished and your opportunities are diminished and perhaps even extinguished. The most frightening part of all of this is that those in the positions of power tend to believe that they are right to do this, that they are right to support "legitimate" research, and that the research they support is legitimate while the rest is not. Again, this limits creativity, imagination, and progress.

In some recent external grant application reviews that I have been fortunate enough to have shared with me, I read defamatory comments regarding some of the information on some of the curriculum vitas (CVs), which, according to this particular reviewer, bordered on being fraudulent. When investigated further it becomes clear that the differences of opinion are a result of philosophical clashes. The difference is how scholarship is defined and what one believes constitutes scholarship.

Isn't it absurd to make rules around what can be included on a CV or grant application and then act as if the limiting criteria that have been arbitrarily defined are the measure of someone's life's work? As if what is on the CV or grant application can accurately define a person's capability-especially when what can be included is so strictly guarded, decreed, and reviewed by those in power. This is a process where millions of hits on a YouTube video that has a large impact, for example, has no place on an external grant application, and where a peer reviewed article that has had little or no impact has a place. As far as the reviewers are concerned, it is as if the large impact never even happened because of the limits of what can be included in the application. Again, isn't it absurd that helping people in the world can be worth less (or nothing at all) than a peer reviewed paper that has little or no impact? Isn't it time to see people more holistically, and not as mere peer reviewed, conformist automatons?

\section{Schooling as a Philosophy}

Given my experience with schooling, that demands for a narrowly-conceived conformity exist is not surprising, but it still is unconscionable that they do exist. You see, schooling is not something that happens just in schools: it is a philosophy that poisons/infects/ permeates our world. These externally imposed limits on what constitutes scholarship serve to perpetuate the status quo and are driven by schooling's philosophy. It's time to ask seriously: Who benefits? Who doesn't? Why? And most importantly, how can this wrong be righted?

When we see that the most powerful educational thinker of our time decided to live his life away from the gaze of schooling's purview and philosophy, then we should be alerted that this is a strong indication that there is a problem. I have read that Dewey has had the most impact in education during the first half of the twentieth century, and Freire in the second half, but I would like to shout out that John Holt's time is overdue. Here is what Holt (1990) writes in a letter Frank Jennings dated April 17, 1963:

The question is whether I could pursue this study more effectively as a member of the faculty of a university. Granting that I may be wrong in thinking so, I am very firmly convinced that a university tie would hinder my work far more than it would help it. I think this would be so for two reasons, one, that a university would require me to spend a certain amount of time working for them, so to speak, for things that interested them, for their concerns rather than mine. If I 
were attached to a school of education, I would have to teach some more or less conventional courses, on psychology or teaching methods or something or other, and I would have to do a certain amount of professional reading, and a certain amount of writing in professional publications. None of this stuff which I would ordinarily choose to do.

There might be something to be said for spending half my time doing things I did not want to do, if during the other time I could do, with university support, the things I did want to do. But I don't believe this would happen, either. The questions that concern me, in the words of a member of the Harvard school of Education, [are] "not respectable." ... The way I learn requires that I be free to continue to work on this broad, and in military terms, fluid front.....None of them would have been considered a research project as a university ordinarily understands the word. In none of them did I have a clear idea of what I wanted or expected to achieve or learn; the fact is that all of these projects evolved in rather different ways from what I had expected. ..I am truly exploring, and an explorer does not know, when he starts into a bit of unknown country, what he is going to find there. But this is not how most of what passes for educational research is done, or how research proposals are written up. (pp. 27-28)

In part, what I get from Holt's words above is that despite deceptions claiming that we have academic freedom, in the end schooling as a philosophy limits creativity, imagination, and perpetuates the status quo. In short, academics are free as long as they play within the very strict and limiting rules of an archaic game. As an example, I have often heard it said that individuals who had been frozen for 100 years would not be able to function in our world and that our world would be largely unrecognizable to them, but that as soon as they entered a school they would know exactly where they were. Academics need to be encouraged to embrace, create, and be at the forefront of innovations; unfortunately, instead, they are rewarded for conforming to a restraining structure.

\section{Can We Trust the Peer Review Process?}

In my experience, papers are often rejected not because the content is poor, but because the author resisted and did not conform to a specific, rigid and limiting formula, all under the guise of academic rigour. For example, in a traditional paper my words and thoughts would not be sufficient to make it through a peer reviewed process, but if I say the same things and cite others who have supported the arguments I have already made, then a reviewer will likely look upon this as more appropriate (conformist), and this will more likely lead to my paper being published. In short, a literature review needs to be included. Is this consistent with academic freedom and academic innovation or does it insist that particular and specific traditions are maintained? It is clear that content is not enough and that format and conformity to a specified formulaic methodology is valued.

Who reviews your work can be more important than the content of your work. The peer review process is not an objective neutral process that tries to coach writers in a gentle way to get their work published, but it is too often a brutal, punitive, and frustrating process of maintaining a tradition.

In "Vagaries and Politics of Funding Educational Research," Michael Roth (2005) writes the following:

I have become quite disillusioned with the peer review process after an experience with one of the highest ranked journals in education.... I had submitted an article that was returned, after a lengthy period, with two recommendations for "rejection." I took the article, gave it a new title but changed nothing in the body of the text and then submitted it to the same journal. This time it came back highly rated with one "accept as is" and one "accept with minor changes." (p. 310) 
In her article "Publish-or-perish culture at universities harms public good: scholar," Pauline Tam (2007) writes the following:

Harry Arthurs told an Ottawa conference of academics yesterday that ivory-tower careers are increasingly measured by the volume of research published by scholars and the amount of grants they attract, resulting in the corruption of academic values such as honesty, integrity and knowledge produced for the public good. (Nov. 3, p. A4)

My point in sharing the above examples is to emphasize that the peer review process is not as pure as we would like to think. It has some negative and questionable practices associated with it. It is not as objective and neutral as we would like to believe. It is not untainted by abuse, intentional, unintentional, procedural, or otherwise. In Poisoned Apples (2008), I ask the question, "Is the peer review process utilized in academia as a process of quality assurance or is it a process of thought control that victimizes its unwilling participants who have little choice but to partake?" (p. 94). I want to reiterate here that, unfortunately, the latter plays a powerful role in the process.

This attitude is an insult to other forms of scholarship. For example, among the two most circulated educational magazines are Educational Leadership and Phi Delta Kappan. While many educational journals have a readership in the hundreds or low thousands, Educational Leadership has a readership of 185,000 and Phi Delta Kappan has a readership of 65,000 (Henson, 2007, p. 782). Remember that these are not refereed (Henson, 2007, p. 784), but are highly reputed editorial magazines that many turn to for guidance. How is it that a double blind review of a paper holds more clout than a magazine that uses an editorial board? It is time to rethink this absurdity and begin to value a wider breadth of scholarship. It seems as if those who hold onto the current system do so because it is a convenient and practical way to evaluate scholarship, but at what cost? How many innovate and creative people are being overlooked because they are not playing within the rules of the game, and not because they are incapable?

What can we do? There are things we can do to expand the definition of scholarship. First, we need to embrace, encourage and value scholarship that uses new technologies and innovative ways to disseminate information and expand access to ideas that, hopefully, will ultimately have a positive impact in the world we live. Second, we need to make our work freely available and more easily accessible. Doing this, John Willinsky (2006) points out, will result in a greater advantage to us and to the community at large. In part, the argument goes as follows: the more accessible our work is, the more people can have access to it, the more people are likely to read it, cite it, and hopefully incorporate it into their daily lived experiences. As well, at the 2007 Ministry Days held at the Ontario Institute for Studies in Education at the University of Toronto, James Heap, the keynote faculty speaker, suggested that scholarship that gets media attention needs to be highly valued.

In conclusions, we should expand our definition of scholarship to include all kinds of different, innovative, creative, and forward moving forms. We should encourage those who are innovators, and not punish them for being pioneers. Academics should be doing the most serious, real work; instead, the current rules reduce our noble profession to a mere game where we put off serious work to insure that we are playing the game in search of increasingly fewer biscuits.

\section{References}

Henson, K. (2007, June). Writing for publication: Steps to excellence. Phi Delta Kappan, 88(10), 776-780. Holt, J. (1990). To Frank Jennings: April 17 [1963]. In Susannah Sheffer (Ed.), A life worth living (pp. 2629). Columbus, OH: Ohio State University Press. 
Ricci, C. (2008). Poisoned apples: An insider exposes the victimization, abuse, politics, associated pain and solutions to our educational crisis. Retrieved February 8, 2010, from http://www.nipissingu.ca/ education/carlor/books/Poisoned Apples.pdf

Roth, M. (2005). Vagaries and politics of funding educational research. In M. Roth (Ed.), Auto/Biography and Auto/Ethnography: Praxis of research method (pp. 301-330). Rotterdam, NL: Sense Publishers.

Tam, P. (2007). Publish-or-perish culture at universities harms public good: scholar. The Ottawa Citizen. Retrieved May 27, 2008, from http://www.canada.com/ottawacitizen/news/ story.html?id=6afef267-bb4d-4d06-a9f1-2078efe4416e

Willinsky, J. (2006, May). Just be open about it: Scholarly publishing as public trust and public good. In J. Kincheloe (Chair), The changed boundaries and possibilities of publishing: Issues of access, reach, genre and textuality (Symposium/Colloque). Symposium conducted at the Canadian Society for the Study of Education, Toronto, Canada. 